\title{
Macromolecular biophysics of the plant cell wall: Concepts and methodology
}

\author{
Michael C. Jarvis ${ }^{a *}$, Maureen C. McCann ${ }^{b}$ \\ ${ }^{\text {a }}$ Chemistry Department, Glasgow University, Glasgow G12 8QQ, Scotland, UK \\ ${ }^{\mathrm{b}}$ Department of Cell Biology, John Innes Centre, Colney, Norwich NR4 7UH, England, UK \\ * Author to whom correspondence should be addressed (fax +44 141330 4888; e-mail mikej@chem.gla.ac.uk)
}

(Received June 29, 1999; accepted November 3, 1999)

\begin{abstract}
Plant cell walls provide form and mechanical strength to the living plant, but the relationship between their complex architecture and their remarkable ability to withstand external stress is not well understood. Primary cell walls are adapted to withstand tensile stresses while secondary cell walls also need to withstand compressive stresses. Therefore, while primary cell walls can with advantage be flexible and elastic, secondary cell walls must be rigid to avoid buckling under compressive loads. In addition, primary cell walls must be capable of growth and are subjected to cell separation forces at the cell corners. To understand how these stresses are resisted by cell walls, it will be necessary to find out how the walls deform internally under load, and how rigid are specific constituents of each type of cell wall. The most promising spectroscopic techniques for this purpose are solid-state nuclear magnetic resonance (NMR), and Fourier-transform infrared (FTIR) and Raman microscopy. By NMR relaxation experiments, it is possible to probe thermal motion in each cell-wall component. Novel adaptations of FTIR and Raman spectroscopy promise to allow mechanical stress and strain upon specific polymers to be examined in situ within the cell wall. (C) 2000 Éditions scientifiques et médicales Elsevier SAS
\end{abstract}

\section{Cellulose / growth / mobility / pectin}

CP, cross-polarisation / FT, Fourier-transform / IR, infrared / MAS, magic-angle spinning / NMR, nuclear magnetic resonance $/ T_{2}$, spin-spin relaxation time constant

\section{INTRODUCTION}

This review deals with plant cell walls at the macromolecular level, from the viewpoint of their function of providing strength and shape to the living plant. It is focused on new and developing methods for investigating the functional architecture of the cell wall and the effects of mechanical stress upon it. First, however, we will put our subject into the context of classical plant biophysics by briefly reviewing how the biomechanics of the cell wall are related to those of intact plants.

\section{MACROSCOPIC CELL-WALL BIOPHYSICS}

\subsection{Cell walls and the mechanical properties of plant tissues}

The environment of a plant (figure $1 \mathrm{~A}$ ) subjects it to a great variety of mechanical stresses [42]. Gravity is always present. Its effects can be augmented by rain or become violent when a falling apple hits the ground. Strong winds bend trees and flower-stalks and tear at the edges of fluttering leaves. The plant also generates its own internal stresses, due to turgor, growth or the negative pressure within the xylem [45]. At the level of a single cell wall, these stresses resolve into tension or compression in the plane of the wall, or cell separation perpendicular to that plane (figure $1 \mathrm{~B}$ ). Plant cells have two ways of withstanding these stresses. The first strategy is for all compressive stresses on the tissue to be taken by the turgor pressure within the cell $[20,42]$. The cell walls are then maintained permanently in tension and are adapted for this tensile function. In the second strategy, the cell wall withstands both compressive and tensile stresses.

Strategy 1 is associated with primary cell walls. It is highly efficient for a small, growing plant, because it provides rigidity and strength with a remarkably small 


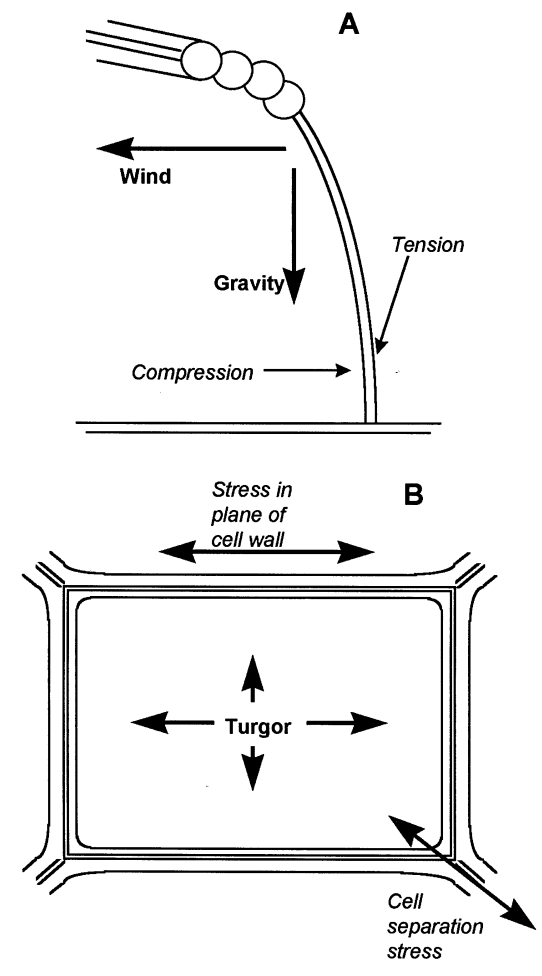

Figure 1. A, Environmental stresses on whole plants: origin of compressive and tensile stresses on stems. B, Stresses induced on cell walls by turgor pressure.

investment of material $[31,43]$. In root crops or unripe fruit, the mass of cell-wall polymers may be less than $2 \%$ of the total mass of the turgid tissue. The most advanced rigid polymer foams, used for example in aircraft construction, can hardly compare with these plants' ratio of stiffness to structural mass. The rigidity of the tissue does not depend on the cell walls being rigid any more than rigidity is needed in the skin of a balloon, and indeed flexibility may help the cell to withstand impact stresses.

The dependence of strategy 1 on turgor pressure brings certain complications. Obviously, when plants using this strategy lose so much water that turgor pressure cannot be maintained, they wilt: the source of their rigidity is lost. This means that extensibility of the cell walls can be an advantage. A cell with walls that are less rigid than normal in tension will be more distended in volume at a given turgor pressure, provided that it does not burst [31]. It can therefore afford to lose more water, without becoming flaccid, than a cell with rigid walls.

Turgor pressure also generates forces tending to separate the cells at the corners, because a sphere has the maximum volume for a given surface area (figure 1 $B)$. These cell separation forces are quite large, comparable with the turgor force stretching the cell wall in its own plane, and because they scale with the cell diameter, they may well be the principal factor limiting cell size in multicellular plants [24].

Strategy 1 is the most economical way to build a plant, but it suffers from a limitation of scale. Wind bending a flower-stalk exerts a compressive stress on the inside and a tensile stress on the outside of the bend (figure 1 A). These scale with the square of the height of the plant. In addition, its weight augments the compressive stress to an extent that scales with the cube of the plant's dimensions. There is a limit, therefore, to the size of a plant that can be supported by practicable levels of turgor and beyond this limit, the cell walls themselves must supply the necessary strength in compression. When plants grow taller to compete for light, the adaptive result is strategy 2 : secondary cell walls as in wood. An elongated structure in compression will normally fail by buckling, and its elements need above all to be rigid to prevent this [42]. Rigidity demands thick cell walls, and the investment of wall material (excluding water) is therefore typically an order of magnitude greater than in strategy 1 . Cells with lignified, secondary wall thickenings are not normally capable of growth, and woody plants therefore require growth to take place outside the woody tissues. In trees, this necessitates a secondary meristem.

A special case of strategy 2 is xylem vessels. The taller the plant, the greater the negative pressure inside these as they supply water for transpiration at the top, and the more they are compressed radially by the cells around them at the base of the stem [45]. In herbaceous plants, these stresses are normally carried by spiral secondary wall thickenings that can stretch like coil springs when the primary wall of the xylem vessel elongates. In this case, the two strategies occur together, but normally they are mutually exclusive in dicotyledonous plants. In grasses, cereals and certain related monocotyledonous families like the palms, the structural and functional distinction between primary and secondary cell walls is not so clear and needs closer examination in relation to development and growth $[5,27,50]$.

\subsection{The growing cell wall}

Expansion of cell walls is obviously a necessary component of the growth of plants, and the control of cell-wall expansion is one of the ways in which plant growth is controlled and directed. Cell-wall expansion 
is driven by the turgor pressure inside the cell but under constant turgor, it is permitted and controlled by the mechanical behaviour of the cell wall itself. It is necessary for the structure of the wall to loosen, but continuous growth does not result in any loss of strength so the synthesis of new material and its incorporation in the cell wall are also required. The manner in which wall loosening and synthesis are integrated is unclear.

In mechanical terms, the extension of a plant cellwall under turgor pressure is formally equivalent to creep, because it is approximately linear with time [8]. There is a close similarity between the mechanical concept of creep and the rheological concept of viscous flow, which is also linear with time. However, cell-wall extension differs from Newtonian viscous flow in two important respects; it is normally under directional control, and it does not occur until a threshold stress is reached. Considering wall extension as creep in the mechanical sense is useful for designing experiments to measure it, but is probably not very useful for understanding what is happening inside a cell wall while it extends. For this, it is not enough to consider the cell wall as a material. We need to know not only how its component polymers are interconnected and how the resulting network deforms during extension, but also how new polymers are incorporated into the network. At present, much of this knowledge does not exist.

The discussion above allows us to summarise the principal stresses that cell walls must resist, or to which they must yield during growth. Primary cell walls are characteristically held in tension created by turgor pressure. They need to be strong in tension but they need not be very rigid, either in tension or in bending. The controlled, often highly anisotropic and localised expansion of the primary cell wall under turgor pressure is essential, although not sufficient, for growth. Cells with primary walls must withstand separation forces at the corners, forces that tend to pull apart the middle lamella and delaminate the primary wall.

Secondary cell walls are subjected to both tension and compression, and must be as rigid as possible to avoid buckling in compression. Buckling of the tissue is also prevented by fusing a group of cells into a wider column: strong connections across the middle lamella, particularly rigid in shear, are required for this function. The spiral secondary thickenings of immature xylem cell walls need some rigidity to prevent the vessel from being crushed by positive pressure in the surrounding cells, but their shape is well adapted for this and they need some elasticity to permit elongation growth.

\section{METHODS FOR INVESTIGATING ARCHITECTURE AND MECHANICAL FUNCTION AT THE MOLECULAR LEVEL}

\subsection{Cell-wall spectroscopy}

How can we find out how cell walls resist mechanical stress, or how the walls of growing cells expand in response to the stress of turgor? By conventional mechanical testing on macroscopic plant specimens, it is possible to make deductions about the internal distribution of stress and deformation within the cell walls. This approach has reached some degree of sophistication for woody materials [19] and more limited progress has also been made with primary cell walls. However, it requires the behaviour of the cell wall to be fitted to models derived for synthetic polymer materials. For hydrated primary cell walls in particular, the fit is not satisfactory because these cell walls are not materials; they are structures and their architecture matters.

It is clear that the functional characteristics of cell walls depend on fine details of their macromolecular structure and conformation, and on their highly ordered architecture at scales from a few nanometers (i.e. just above the molecular scale) to several microns. Much of this fine detail is lost when cell-wall polymers are extracted into solution, as is necessary before they can be examined by the classical techniques of polysaccharide, protein and lignin chemistry. There is therefore an important role for spectroscopic techniques that can be used to examine plant cell walls in their native state, without prior fractionation or solubilisation. In addition, there are ways in which two of these techniques, vibrational and NMR spectroscopy, can be used to probe internal stress-strain relationships more or less directly at the molecular level. In principle, this approach, unlike conventional mechanical testing, is not dependent on materials science and its models for deducing molecular behaviour from macroscopic behaviour.

Plant cell walls are usually considered as solids, although in their native state, water comprises more than half of their mass. This leads to experimental complications. Because solid-state spectroscopic techniques have been developed principally for synthetic polymers, the presence of water is a problem that has not been much studied. When cell-wall biopolymers 
Table I. Wavelength and frequency (wave-number) scales for vibrational and visible spectroscopy. IR, infrared.

\begin{tabular}{lcccccccrrr}
\hline Waveband & \multicolumn{3}{c}{ Visible } & \multicolumn{3}{c}{ Near-IR } & \multicolumn{3}{c}{ Mid-range IR } \\
\hline Wavelength $(\mu \mathrm{m})$ & 0.40 & 0.70 & 1.00 & 1.75 & 2.50 & 4.38 & 6 & 11 & 16 \\
Frequency $\left(\mathrm{cm}^{-1}\right)$ & 25000 & 14300 & 10000 & 5700 & 4000 & 2300 & 1600 & 900 & 640 & 400 \\
\hline
\end{tabular}

interact with water in ways that fall between the classically-defined solid and solution states, the physical chemistry available to describe these states may be disconcertingly inadequate.

For these reasons, the first application of individual spectroscopic techniques in this field has in many cases been to materials such as cellulose that usefully can be studied dry, and their adaptation for hydrated cell walls has followed later. The history of cell-wall spectroscopy has been quite long but discontinuous, and has taken separate courses in the cellulose and plant science communities. There have been significant advances whenever ideas have been exchanged between these two communities. The historical format of the following discussion may reveal lessons for the future of this field, and also outside either plant or cellulose science. In terms of the relationship between structure and mechanical properties, plant cell walls are now understood better than any other biological 'soft solids', and the methodology for their characterisation is relevant to poorly understood mammalian materials such as cartilage, skin and arterial walls.

\subsection{Vibrational (infrared absorption and Raman) spectroscopy}

Covalent bonds in any molecule can behave like coil springs, vibrating along their axis or bending. When there is an electric dipole between the two ends of the bond, its vibrations can interact with the electric wave component of light, if they are matched with it in frequency and orientation. For simple vibrations within molecules, the matching frequency range of the spectrum is the mid-range infrared $\left(400-4000 \mathrm{~cm}^{-1}\right.$, corresponding to wavelengths of about $10 \mu \mathrm{m}$, table I). As in music, molecular vibrations can have overtones at higher frequencies and these fall into the near infrared spectral range $(1-2.5 \mu \mathrm{m})$.

Radiation polarised with its electric vector in one direction will only interact with similarly oriented molecular vibrations. This means that vibrational spectroscopy can be used to determine molecular orientations and, apart from the visualisation of individual molecules by electron or atomic force microscopy, it is the only available way of doing this. Polarised IR spectroscopy has great potential for investigating the structure of cell walls at just above the molecular level, where there is strong anisotropy in both architecture and mechanical properties.

An internal vibration in a molecule can either absorb radiation of the right frequency, or scatter it after absorbing some of its energy, hence, reducing its frequency. Absorption is the basis of conventional IR spectroscopy, while scattered radiation gives Raman spectra. Absorption spectroscopy works best with vibrations of asymmetrical (e.g. O-H) bonds, while Raman spectra are of higher intensity when the bonds are symmetrical (e.g. C-C). In practice, carbohydrates and lignin give both IR absorption and Raman spectra, and many of their vibrational modes appear in both [4, 49, 52]. Absorption spectra are easier to collect using simpler instrumentation, but sometimes as with lignin, the Raman spectra are more useful [1, 3].

Shortly after commercial IR absorption spectrometers first became common in the 1950s, the technique was taken up by cellulose chemists and the quality of some of the data collected then is still impressive today $[30,55]$. The deduction of $\mathrm{O}-\mathrm{H}$ bond orientations from polarised IR spectra played a significant part in the development of ideas on cellulose structure $[4,30]$. However, difficulties arose because the spectra were more complex than could be explained from existing structural knowledge. This complexity became attributed to complex coupling between vibrations of groups of bonds within the structure [4, 38] and the difficulty of interpreting the spectra caused some disillusionment with this application of the technique. In retrospect, this was unjustified: it was not realised at the time that all natural cellulose contains two distinct forms, cellulose I $\alpha$ and I $\beta$ [2] and that within each form, there is some variation in the details of chain conformation and interchain hydrogen bonding. Unlike, for example, NMR, vibrational spectra are not significantly averaged over nanosecond timescales. In consequence, even if two interchain hydrogen bonds in cellulose equilibrate rapidly, O-H stretching bands from both will be observed in the IR spectra, whereas in NMR, they may give rise to a single spectral feature. Thus the complexity of the $\mathrm{O}-\mathrm{H}$ 
stretching region of the cellulose IR spectrum, at least, can be explained by the range of structures present.

During the 1950s, the use of IR spectroscopy was extended to xylans and other components of wood cell walls, largely by Marchessault and co-workers in relation to paper manufacture [36, 37]. It was not applied to primary cell walls until about 1970, when Morikawa and co-workers [39] showed that pectins as well as cellulose were clearly identifiable in the spectra of Pisum epidermal cell walls and that the mean orientation of both polysaccharides changed with growth. These innovative experiments did not succeed in popularising the technique at the time, but they were noted and encouraged the more recent application of infrared microscopy to cell walls by McCann, Wilson and co-workers [33].

An infrared microscope is essentially a Fouriertransform (FT) spectrometer with the IR beam focused on a very small area of the sample, typically a few $\mu \mathrm{m}$ across. The absorption spectra generated (figure 2) are similar to those obtained in a conventional spectrometer but, even as just a means of obtaining spectra, the microscopy mode has considerable advantages [32]. Cell-wall samples prepared as $\mathrm{KBr}$ discs in a conventional spectrometer give good spectra but because the cell walls are finely ground and dispersed, information on polysaccharide orientation is not preserved. This information can be obtained by polarised IR from films of cell walls about $1 \mu \mathrm{m}$ thick, but the films need to be at least ca. $4 \mathrm{~mm}$ in diameter to fill a standard spectrometer beam and uniform specimens of these dimensions are difficult to prepare, even by cryosectioning. In microscopy, this is not a problem. Polarised IR microscopy (figure 3) also has the advantage that an oriented spectrum can be obtained from a single cell wall with the radiation beam passing up through it at right angles [32]. When a larger area of tissue section is viewed in the same way in a conventional spectrometer, some of the cell walls are vertical, parallel to the beam. Because cellulose microfibrils are normally in the plane of each wall of a cell, these vertical walls make an unjustified contribution to the mean microfibril orientation observed. With an IR microscope, this problem can be avoided.

The molecular vibrations that give rise to the fingerprint region of the spectrum (1000-1 $\left.400 \mathrm{~cm}^{-1}\right)$ are quite complex, mostly involving simultaneous movement of numbers of ring carbon atoms [4]. They are therefore difficult to interpret from first principles although this has been attempted for cellulose [4]. Until recently there has been more interest in bands just outside this spectral region, derived from pectic

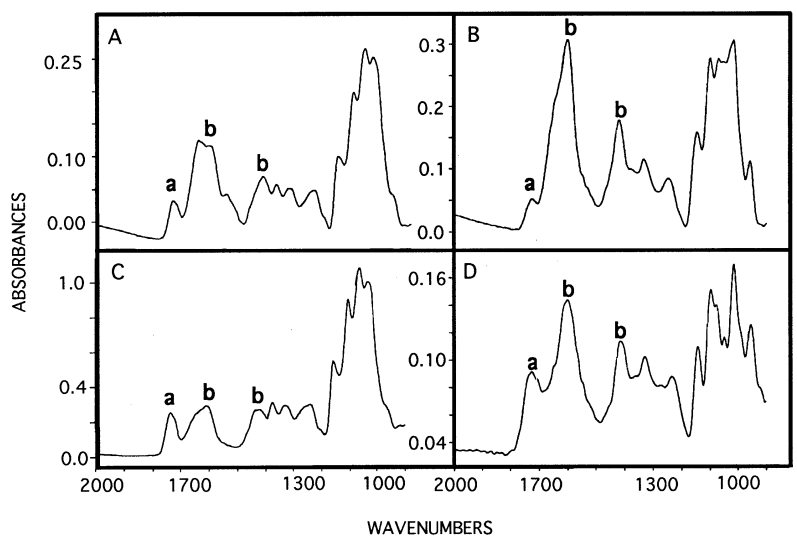

Figure 2. Infrared transmission microspectrometry of primary cell walls: $\mathbf{A}$, cell walls from tomato cell suspension cultures; $\mathbf{B}$, cell walls from tomato cell suspension cultures adapted to the herbicide 2,6dicholorobenzonitrile, which inhibits synthesis of microfibrils, leaving the cell wall enriched in pectin; $\mathbf{C}$, onion parenchyma cell walls; $\mathbf{D}$, galacturonan (Sigma). Symbols: a, ester carboxyl; b, carboxylate ions.

carboxyl groups or lignin rings [33, 39]. However, the recent introduction of principal components analysis of the spectral data (figure 4) makes it possible to extract the spectral contributions of individual poly-

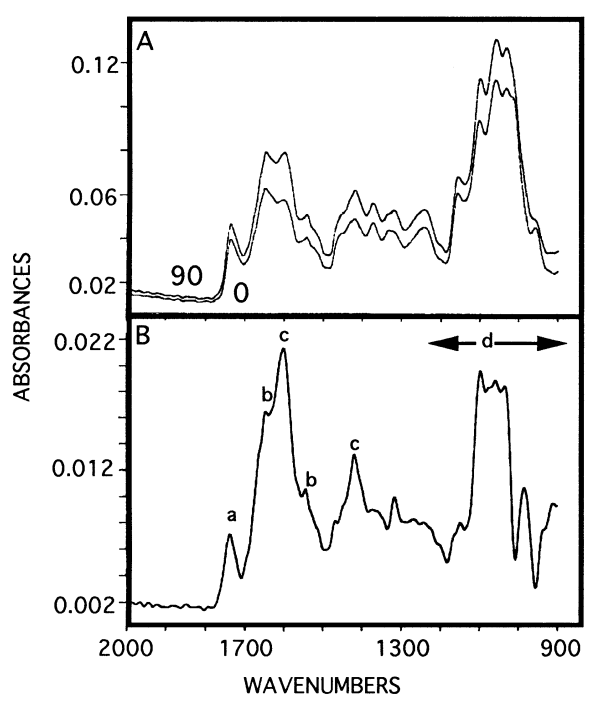

Figure 3. Polarised infrared spectra of elongating stem tissue from carrot seedling. A, Spectra with polarisation parallel (0) and perpendicular (90) to the direction of cell elongation. B, Difference spectrum (90-0) showing orientation of (a) pectic ester $\left(1740 \mathrm{~cm}^{-1}\right)$, (b) peptide (1 650 and $\left.1550 \mathrm{~cm}^{-1}\right)$, (c) pectic carboxylate ion $(1600$ and $1414 \mathrm{~cm}^{-1}$ ) and (d) general carbohydrate $\left(900-1200 \mathrm{~cm}^{-1}\right)$ vibrations. 


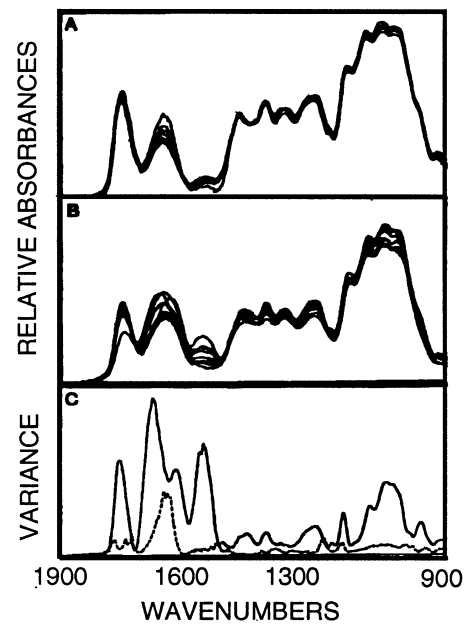

Figure 4. Variance of infrared spectra from primary walls of apple and ten other species. A, Cell walls from ten different apples. B, Cell walls from ten species other than apple, showing wider variation than in A. C, Variance spectra from the two data sets, showing spectral regions in which variability is localised. (----) Apple; (-) other species.

mers whose composition, estimated by other forms of analysis, varies across a large sample population [7]. This approach, in principle, allows the abundant information in the fingerprint region to be used without a detailed understanding of the molecular vibrations from which it originates. Some care is however necessary because polysaccharide chain conformations can have a large influence on the spectra. Indeed there is considerable potential for investigating the conformations of cell-wall polysaccharides in situ by this means, and a change in the conformation of pectic galacturonan on drying has been observed through its influence on this region of the IR spectrum [32].

The hydroxyl stretching region of the spectrum (3 000-3 $500 \mathrm{~cm}^{-1}$ ) contains information on hydrogenbonding patterns $[30,36,55]$. It is not the stretching of the hydrogen bond itself that is observed, but conventional $\mathrm{O}-\mathrm{H}$ bonds are weakened and their stretching vibrations moved to lower frequency if the proton is hydrogen-bonded to another oxygen atom. This region of the cellulose spectrum has been studied intensively since forty years ago but for intact cell walls, it is less useful because hydration and disorder create a broad dispersion of vibrational energies. However, deuteration of the free hydroxyl groups moves all of this IR absorption to lower frequency by a factor of 1.34 (due to the extra mass of the D atom), with the exception of the interior chains of cellulose which are well-ordered and too tightly hydrogen-bonded to deuterate [55].

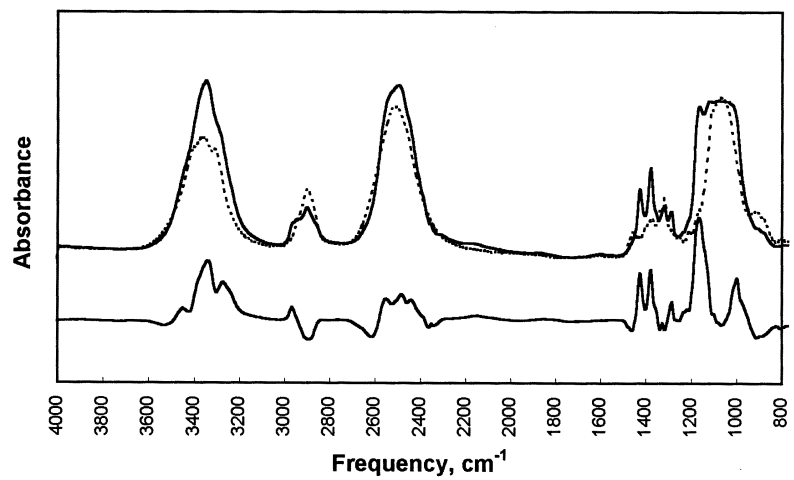

Figure 5. Polarised infrared spectra of single deuterated fibre cell of flax. Hydroxyl stretching bands are moved from ca. 3500 to ca. $2500 \mathrm{~cm}^{-1}$ by exchange with deuterium, except for the interior chains of cellulose I $\alpha$ and I $\beta$ which do not deuterate. Polarisation (-) parallel and (-----) transverse to the fibre axis; difference spectrum below.

This reveals detailed hydroxyl spectra (figure 5) of cellulose showing such features as the $I \alpha / I \beta$ ratio and the chain orientation.

By selecting a small aperture and scanning the specimen past the beam, it is possible to construct images based on IR spectral data [32]. The aperture size and, hence, the spatial resolution are limited by the wavelength of mid-infrared radiation. The resolution is then considerably inferior to that of visible light microscopy. Details of the wall composition of individual cells can normally be observed, and the resulting images give a fascinating visual insight into functional plant anatomy through the varying composition of the cell walls (figure 6). Structural details that vary across the thickness of the cell wall, however, are outside the spatial resolution of IR microscopy.

Raman spectroscopy and imaging are also possible at the microscopic level [1, 3], and their potential spatial resolution is superior when the incident radiation used is in the near-infrared waveband, with shorter wavelength. So far, Raman microprobe spectrometry has been more successful for lignified cell walls, such as those of wood, which is difficult to section for transmission FTIR microspectrometry.

Mid-range vibrational spectroscopy therefore has considerable utility for elucidating the composition, conformation and orientation of polysaccharides within intact plant cell walls, particularly when the information can be expressed in image form and related to anatomy and development. It also has potential for investigating what happens inside a cell wall under mechanical stress, and this promises to be 


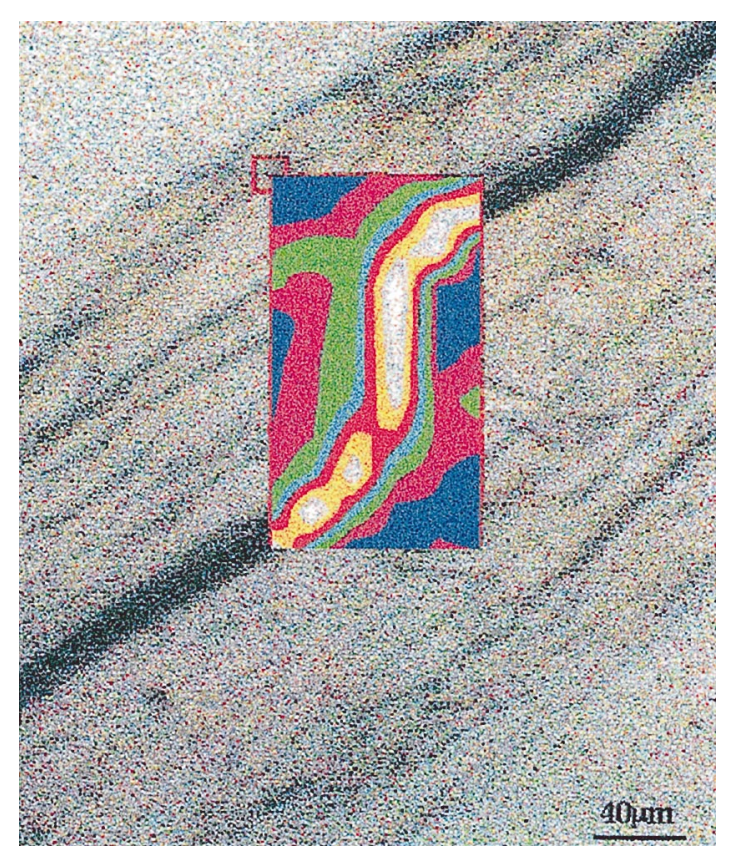

Figure 6. Infrared microspectral imaging. Longitudinal section of the stem of an Arabidopsis seedling with false colour showing the ratio of ester to non-esterified pectic carboxyl; high level of ester along the central vascular strand.

the key to a new way of understanding the functional architecture of the cell wall.

There are two complementary ways in which this question can be approached. The first is by twodimensional mechanical/FTIR spectroscopy, where polarised FTIR is used to probe changes in the orientation of polymers in or out of phase with an applied, oscillating mechanical stress. This approach has been developed to a considerable degree of refinement for synthetic polymers by Noda [44], and appears to have great potential for characterising the internal deformation of the structure of the cell wall under mechanical stress.

Application of two-dimensional FTIR spectroscopy to onion epidermal cell walls showed that both cellulose and pectin bands changed in their vibrational orientation in response to a mechanical oscillation at $20 \mathrm{~Hz}$, but lagged behind the imposed oscillation to different extents. This indicates that both pectic polysaccharides and cellulose deformed under the applied stress, but that they did so independently (M. Kacurakova and R.H. Wilson, unpubl. results).

In the second technique, changes in the force constants of chemical bonds bearing mechanical stress are observed through small changes in their stretching vibrational frequency [56]. Unlike the first approach, it probes stress rather than strain. For synthetic polymers, the Raman spectroscopy method is quite well developed and has recently been applied to cellulose [16], showing how the glycosidic bonds in the cellulose polymer carry tensile stress. The application of these two complementary methods to intact cell walls is awaited with interest.

\subsection{Solid-state NMR}

NMR, like infrared spectroscopy, has a long history but it is only since about 1980 that it has been technically possible to obtain high-resolution NMR spectra from most types of solids. NMR spectroscopy probes the three-dimensional distribution of electrons that is responsible for all types of chemical bonding. It does this through the tiny magnetic fields created at the nucleus by orbiting electrons. Cell-wall polysaccharides in solution give detailed and highly informative ${ }^{13} \mathrm{C}$ and ${ }^{1} \mathrm{H}$ NMR spectra. However, if intact cell walls are examined in a conventional, solution-state NMR spectrometer, the ${ }^{13} \mathrm{C}$ or proton spectrum is so broad that it cannot be seen. This is because for each chemically distinct atom there is a wide range of possible orientations and possible dipolar interactions with neighbouring atoms. These effects are averaged out by rapid thermal motion in solution, but not in the solid state [51].

Solid-state ${ }^{13} \mathrm{C}$ NMR became a practical possibility in the late 1970s with the introduction of high-speed magic-angle spinning (MAS) and high-power dipolar decoupling, which provide alternatives to thermal averaging of these broadening effects [51]. This is achieved at a cost. A specialised NMR spectrometer is needed for working with solids, with a wide-bore superconducting magnet to accommodate the complex probes required. Dipolar decoupling requires a controlled input of radiofrequency energy rather like in microwave cooking, and care may be needed to prevent the sample from overheating. Magic-angle spinning at $2-5 \mathrm{kHz}$ (up to $20 \mathrm{kHz}$ on some modern spectrometers) means that the sample is subjected to centrifugal forces comparable with those in an ultracentrifuge, so that it is not in an unstressed condition and water is difficult to retain in hydrated samples. It also rules out the possibility of studying the effects of controlled mechanical stress on the sample, and normally restricts the sample size to about $0.1 \mathrm{~g}$ so that some thousands of repetitions of each spectral measurement must be averaged to obtain an adequate signal/noise ratio. This can lead to very long durations for ${ }^{13} \mathrm{C}$ NMR experiments. These can be reduced by 
cross-polarisation $(\mathrm{CP})$ or transfer of magnetisation from ${ }^{1} \mathrm{H}$ to ${ }^{13} \mathrm{C}$ for measurement, mainly because ${ }^{1} \mathrm{H}$ magnetisation returns to equilibrium much faster than ${ }^{13} \mathrm{C}$ so that each repetition requires about $1 \mathrm{~s}$ rather than $1 \mathrm{~min}$. The CP-MAS experiment, with highpower decoupling, has become the standard way of recording NMR spectra from organic solids [51].

Solid-state ${ }^{13} \mathrm{C}$ NMR spectroscopy can be useful for detecting features of primary structure that are lost on dissolution or cannot be solubilised, like lignification [54] or cutinisation [15] (table II). It is not sensitive enough, however, to detect the relatively rare covalent cross-links that are assumed to be important in holding cell-wall polymers together in insoluble networks. Since its inception, it has been used successfully for investigating polysaccharide conformations in muro. The conformational distinction between the $\mathrm{I} \alpha$ and I $\beta$ forms of cellulose was discovered in this way shortly after the CP-MAS technique was introduced $[2,21]$, as more recently was the broad range of chain conformations adopted by pectic galacturonans within the cell wall $[14,25,53]$.

A unique advantage of solid-state NMR is its sensitivity to thermal motion in polymers. This approach has been worked out in detail for examining the molecular basis of mechanical properties in synthetic polymers and its potential for understanding how the plant cell wall functions was recognised at an early stage by Irwin et al. [22]. These initial results were not promising because Irwin worked only with dry cell walls, in which thermal motion is restricted and not closely related to mechanical properties. For a period after this, interesting data on proton mobility were collected by Taylor and co-workers [35] using broadline ${ }^{1} \mathrm{H}$ NMR methods, which do not require magic-angle spinning. However, individual polymers cannot be resolved in the broadline ${ }^{1} \mathrm{H}$ spectra. Some five years ago, a number of groups simultaneously found solutions to the practical problems of doing solid-state CP-MAS ${ }^{13} \mathrm{C}$ NMR experiments on hydrated cell walls $[11,26,41]$ and since then, quite a
Table II. Distinctive peak assignments in ${ }^{13} \mathrm{C}$ NMR spectra of primary cell walls. Asterisked chemical shifts are variable depending on the polymer chain conformation.

\begin{tabular}{llc}
\hline Polymer & Carbon & $\begin{array}{c}\text { Chemical shift } \\
(\mathrm{ppm})\end{array}$ \\
\hline Galacturonan & COONa & 177 \\
Galacturonan & COOCa & 175 \\
Acetyl & COOR & 173 \\
Galacturonan & COOH & 173 \\
Galacturonan & COOCH & 171 \\
Feruloyl ester & COOR & 168 \\
Arabinan & $\mathrm{C}-1$ & 109 \\
Cellulose, $\beta$-glucan & $\mathrm{C}-1$ & 105 \\
Galactan & $\mathrm{C}-1$ & 105 \\
Xylan & $\mathrm{C}-1$ & 102 \\
Galacturonan & $\mathrm{C}-1$ & $96-101^{*}$ \\
Cellulose I & $\mathrm{C}-4$ & 89 \\
Cellulose (surface) & $\mathrm{C}-4$ & 84 \\
Xyloglucan, xylan & $\mathrm{C}-4$ & $81-84^{*}$ \\
Galacturonan & $\mathrm{C}-4$ & $77-81^{*}$ \\
Galactan & $\mathrm{C}-4$ & 78 \\
All glycans & & $72-76$ \\
Galacturonan & $\mathrm{C}-2, \mathrm{C}^{*} 3$ & 69 \\
Cellulose I & $\mathrm{C}-6$ & 66 \\
Xylan & $\mathrm{C}-5$ & 63 \\
Cellulose (surface) & $\mathrm{C}-6$ & 62 \\
Galactan & $\mathrm{C}-6$ & 62 \\
Galacturonan & $\mathrm{COOCH}$ & 54 \\
Cutin & $\mathrm{CH}{ }_{2}$ & 31 \\
Acetyl & $\mathrm{CH}$ & 21 \\
Rhamnose, fucose & $\mathrm{CH}{ }_{3}$ & 18 \\
\hline & & \\
\hline
\end{tabular}

detailed picture of the mobility of the main groups of cell-wall polymers in situ has been constructed.

Thermal motion influences the rates at which nuclear magnetisation is dissipated (relaxed) or transferred in a number of types of NMR experiment (table III). These experiments are possible for both protons and ${ }^{13} \mathrm{C}$ nuclei. Because magnetisation equilibrates rapidly by nuclear spin diffusion within pools of spatially adjacent protons, proton relaxation experiments provide information on the mean mobility within domains a few nanometers across - somewhat

Table III. NMR methods for probing molecular mobility in solids. Each method has a characteristic frequency range for the thermal motion influencing it, and the time constants are averaged over a characteristic domain size by spin diffusion.

\begin{tabular}{llll}
\hline NMR process & Time constant & Motion frequency & Domain size \\
\hline${ }^{1} \mathrm{H}$ spin-lattice relaxation & ${ }^{1} \mathrm{H} T_{1}$ & $10^{8} \mathrm{~Hz}$ & $>10 \mathrm{~nm}$ \\
${ }^{1} \mathrm{H}$ rotating-frame spin-lattice relaxation & ${ }^{1} \mathrm{H} T_{1 \mathrm{e}}$ & $10^{5} \mathrm{~Hz}$ & $1-10 \mathrm{~nm}$ \\
${ }^{1} \mathrm{H}$ spin-spin relaxation & ${ }^{1} \mathrm{H} T_{2}$ & $10^{4} \mathrm{~Hz}$ & $1-10 \mathrm{~nm}$ \\
${ }^{1} \mathrm{H}^{13} \mathrm{C}$ cross-polarisation & $T_{\mathrm{CH}}$ & $10^{4} \mathrm{~Hz}$ & $1-10 \mathrm{~nm}$ \\
${ }^{13} \mathrm{C}$ spin-lattice relaxation & ${ }^{13} \mathrm{C} T_{1}$ & $10^{8} \mathrm{~Hz}$ & $<1 \mathrm{~nm}$ \\
${ }^{13} \mathrm{C}$ spin-spin relaxation & ${ }^{13} \mathrm{C} T_{2}$ & $10^{4} \mathrm{~Hz}$ & $<1 \mathrm{~nm}$ \\
\hline
\end{tabular}


larger than a monosaccharide residue [40]. On the other hand, because the ${ }^{13} \mathrm{C}$ isotope constitutes only $1 \%$ of natural carbon, spin diffusion between ${ }^{13} \mathrm{C}$ nuclei is restricted and ${ }^{13} \mathrm{C}$ relaxation experiments probe the mobility of the specific carbon atom concerned.

Typical results of a proton spin-spin relaxation $\left(T_{2}\right)$ experiment on hydrated onion cell walls [13] are shown in figure $7 \mathrm{~A}$. Using the $\mathrm{CP}$ technique, the information on proton relaxation is transferred into the ${ }^{13} \mathrm{C}$ spectrum so that different polysaccharides can be readily distinguished. The proton $T_{2}$ values recorded for any peak in the ${ }^{13} \mathrm{C}$ spectrum are derived from those protons in the immediate vicinity of the ${ }^{13} \mathrm{C}$ atom and in spin communication with it. The spectral regions corresponding to cellulose have short values of the relaxation time constant $T_{2}$ corresponding to those expected for a rigid more or less crystalline solid. If the cell walls are dry, its non-cellulosic constituents behave quite similarly as was found by Irwin et al. [22] but on hydration, the $T_{2}$ values for the pectic polysaccharides become much longer as thermal motion increases $[13,53]$. An alternative way of presenting these results is shown in figure $7 \mathrm{~B}$, where the ${ }^{13} \mathrm{C}$ spectrum has been digitally separated into subspectra corresponding to domains of high and low thermal mobility [41]. Relaxation data are particularly informative about states of matter within complex solids if they are carried out at a range of temperatures [53].

In the rather different mobility-resolved spectral editing procedure pioneered by Foster et al. [11], the experiment directly generates ${ }^{13} \mathrm{C}$ spectra from polymers with a specific level of mobility. An example of a spectrum from the most mobile parts of the beet cell wall, generated in this way by using MAS together with a proton decoupling method designed for molecules in solution [46], is shown in figure 8. The spectrum is derived entirely from the pectic arabinans, which must therefore be the most mobile or solutionlike components of the beet cell wall. It very closely resembles the spectrum for beet arabinan in solution, showing that the arabinan conformations are averaged to essentially their solution-state values, and that the motions responsible apply to the entire polymer and not merely to individual functional groups. Similar high-resolution spectra have been obtained from pectic galactans in potato cell walls (W.G. Jardine, D.C. Apperley and M.C. Jarvis, unpubl. results) and from both arabinans and galactans in citrus cell walls (D.C. Apperley and M.C. Jarvis, unpubl. results).

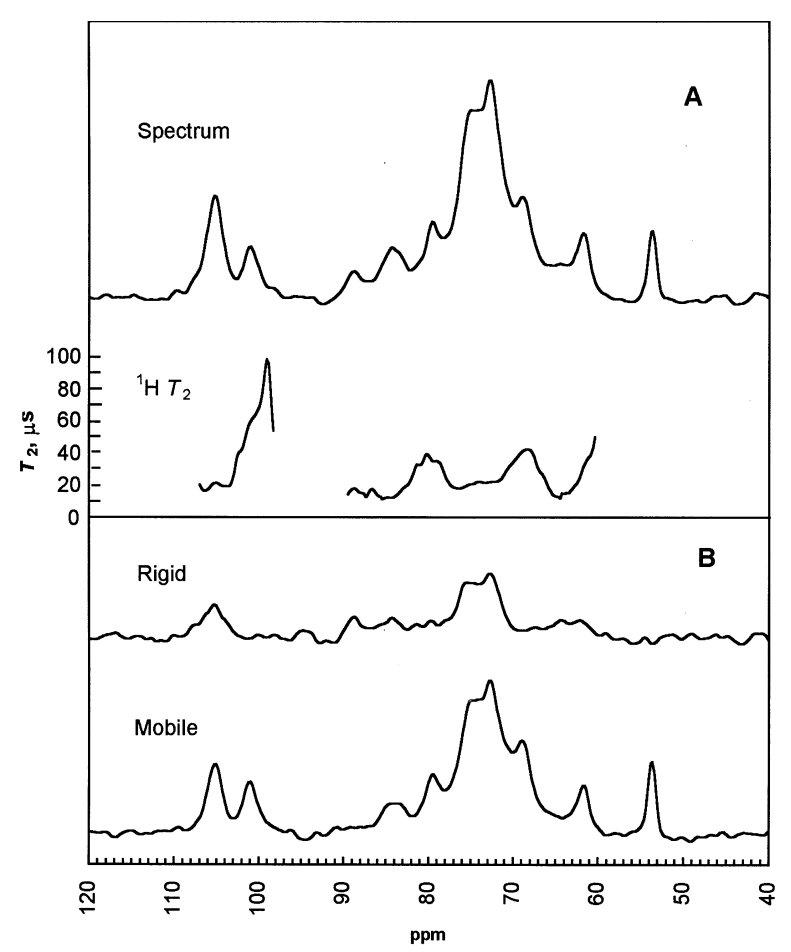

Figure 7. CP-MAS ${ }^{13} \mathrm{C}$ NMR spectra of hydrated onion parenchyma cell walls (A) with proton spin-spin relaxation time constant $T_{2}$ shown below; short ${ }^{1} \mathrm{H} T_{2}$ implies relative thermal rigidity. B, Subspectra corresponding to rigid and mobile components calculated from the same experiment. The rigid component corresponds to the microfibril phase plus strongly cross-linked pectic chains, and the relatively mobile component to more mobile pectins (see assignments in table II). Pectic (1,4)- $\beta$-galactans are missing from these spectra because a short contact time of $50 \mu$ s was used to minimise spin diffusion. The galactans can be observed with longer contact time or in an experiment similar to that shown in figure 8.

It is now possible to summarise how the different polymers vary in their thermal mobility within the intact, hydrated cell wall. Cellulose chains are the most rigid and least hydrated elements in primary cell walls [13, 28, 41], although their surface hydroxyl and exocyclic $\mathrm{CH}_{2} \mathrm{OH}$ groups show considerable rotational motion and proton exchange [17, 21]. When xyloglucans are the major hemicelluloses, the fraction bound to cellulose shares its rigidity, while an unbound fraction with considerably more thermal mobility has been identified [13]. The cellulose and bound xyloglucan may therefore be considered as a solid microfibril phase. Pectic galacturonans cover a broad span of thermal mobility in the region between solids and solutions, with a tendency for highly methyl-esterified segments to show more motion of the main chain as well as the characteristic rotation of the methyl groups. 


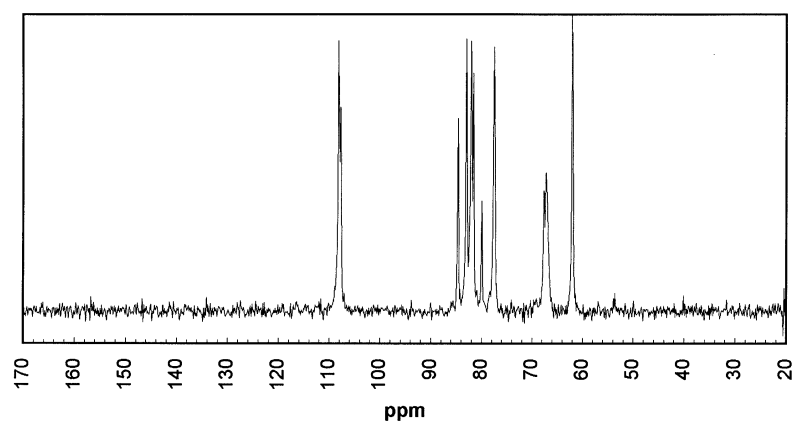

Figure 8. SP-MAS ${ }^{13} \mathrm{C}$ NMR spectrum of hydrated beet cell walls with WALTZ-16 multiple-pulse proton decoupling and 200-ms recycle time to edit out components with ${ }^{13} \mathrm{C} T_{1}$ longer than this. The spectrum is derived specifically from the highly mobile pectic arabinan, all other wall components being too rigid to be observed in this experiment. It shows line-narrowing due to conformational averaging on the NMR time-scale, and resembles the solution-state spectrum of beet arabinan because the averaged conformations are similar to those found in solution.

In pectin-rich cell walls, the most mobile elements are the galactan and arabinan sidechains of the rhamnogalacturonan I fraction, which behave essentially as tethered liquids $[11,46]$.

The primary cell walls of the grasses and cereals have not been so extensively studied by solid-state NMR. In these cell walls, it would appear that arabinoxylans occupy a broad range of mobility, some being nearly as rigid as xyloglucans are in the primary walls of other plants and others as mobile as the pectic galacturonans [50]. No polymer in the oat coleoptile cell wall appeared to be as mobile as the pectic arabinans and galactans (D.C. Apperley and M.C. Jarvis, unpubl. results), but otherwise the range of mobility in the primary cell walls of cereals appears similar to that found in dicots, even though the polymer composition is different [50]. This would be consistent with similar mechanical functions.

In lignified secondary cell walls, the cellulose has similar rigidity to that of primary cell walls, and the rigidity of lignin is comparable [40]. The hemicelluloses of wood are more mobile than cellulose or lignin but, compared with most of the non-cellulosic polysaccharides of primary cell walls, they are still very rigid indeed. There may be some doubt on the states of matter present in hydrated primary cell walls but secondary walls are indisputably solid.

\section{CELL WALLS AS NANOSTRUCTURES: FUNCTIONAL ARCHITECTURE}

Is it possible to assemble an overview from the information already available on internal stress-strain relationships in cell walls? A problem is that at present much of our knowledge comes from solid-state NMR experiments measuring thermal motion of polymer molecules. Thermal motion is not the same thing as deformation in response to an applied stress, and inference from one phenomenon to the other is not simple.

This is a problem encountered commonly by polymer physicists who use NMR methods and some guidelines for dealing with it are available from that field [51]. In particular, it is necessary to concentrate on the thermal motion of the main polymer chain. Motions of side-groups may absorb impact energy in some circumstances but they contribute little otherwise to mechanical properties of the material. Mainchain motion can be used to distinguish crystalline solids, glassy and rubber-like phases, and where two of these types of solid are mingled, there is a considerable body of composite materials science that can be brought to bear in predicting the physical properties of the specimen as a whole $[18,19]$.

With these caveats, NMR relaxation experiments can be used to identify strongly rigid materials like the microfibril phase of the cell wall and to confirm their central structural role. The relatively uniform rigidity of lignified secondary cell walls [40] is consistent, in broad terms, with their function in sustaining compressive stress without buckling. This rigidity arises separately from the crystallinity of the cellulose in the microfibril phase and from cross-linking of lignins in the matrix. A more detailed interpretation of the mechanical properties of secondary cell walls is possible if microfibril angles are included [19].

Primary cell walls present more of a challenge, however. It seems reasonable to suppose that much of their strength and rigidity in the plane of the wall are supplied by layers of cellulose microfibrils. Within each layer, the microfibrils lie approximately parallel and are joined by thin cross-links which have been tentatively identified as xyloglucan chains [34]: if so, these may correspond to the relatively mobile xyloglucan fraction identifiable by NMR [13]. Elongated cells have the microfibrils wrapped predominantly around them and both external tension and growth bring about a more longitudinal orientation of the microfibrils, as well as orienting other cell-wall polymers [10, 32, 39]. This geometry suggests that the 
cross-links may become tensioned, whether due to lateral separation or to shear between the microfibrils [6]. Flexibility would not affect the strength of the cross-linking polymer chains in tension and might even contribute a degree of rubber elasticity [9], but it is not possible to deduce how that might influence the mechanical properties of the cell wall as a whole, let alone its behaviour during growth.

The data available on the swelling of primary cell walls [23] suggest that the pectic polysaccharides hold these walls together across their thickness in addition to bridging adjacent cells across the middle lamella. (This does not rule out an additional role in resisting stresses in the plane of the wall). It seems likely that they form a three-dimensional gel network interpenetrating the microfibril layers. Amongst the pectic polysaccharides, the lowest thermal mobility is found in the linear galacturonan components associated with calcium, which are assumed to form the junction zones that hold the gel together $[14,53]$. The greater rigidity of zones rich in these calcium pectates at the tricellular junctions, where cell separation stresses are greatest, is consistent with this function $[29,47,48]$. They are also enriched when elongation growth terminates $[10,12]$. Other than that, there is no clear indication of how the diversity and complexity of the pectic polymers are related to stress-bearing roles, and in particular, the mechanical role of the highly mobile pectic galactans and arabinans $[11,46]$ is completely unknown.

The role of the more mobile, solution-like polymer chains in hydrated primary cell walls cannot be predicted from the NMR data alone. Although there are now enough data available to describe the chain rigidity of the main polysaccharides in some detail, we need to know also how and where they are attached together, and it is the lack of this knowledge that is now limiting. That is, the properties of the whole primary cell wall cannot be inferred by materials science from the properties of its components, because the wall is a nanostructure and not a material. Some of these problems may be soluble if the new methods based on vibrational spectroscopy $[44,56]$ make it practicable to focus on stress-strain relationships in specific cell-wall polymers in situ.

\section{CONCLUSION}

Plant cell walls are adapted to withstand mechanical stress in extraordinarily sophisticated ways, which are now being revealed by the use of solid-state NMR and vibrational spectroscopy to study them in their native form. Lignified secondary cell walls can be considered as composite solid materials, but hydrated primary cell walls are nanostructures built from polymers that range from crystalline solids to tethered liquids. The ways in which these complex networks respond to mechanical stress can potentially be explored by emerging techniques based on vibrational spectroscopy.

\section{Acknowledgments}

We thank R.H. Wilson and M. Kacurakova for permission to include unpublished material.

\section{REFERENCES}

[1] Atalla R.H., Agarwal U.P., Raman microprobe evidence for lignin orientation in the cell-walls of native woody tissue, Science 227 (1985) 636-638.

[2] Atalla R.H., Vanderhart D.L., Native cellulose - a composite of 2 distinct crystalline forms, Science 223 (1984) 283-285.

[3] Atalla R.H., Haigler C.H., Taylor J.G., Main L.M., Raman microprobe characterization of lignification in the secondary thickenings of differentiating tracheary elements from cultures of Zinnia elegans, Plant Physiol. 114 (1997) 16.

[4] Cael J.J., Gardner K.H., Koenig J.L., Blackwell J., Infrared and Raman spectroscopy of carbohydrates. Paper V. Normal coordinate analysis of cellulose I, J. Chem. Phys. 62 (1975) 1145-1153.

[5] Carpita N.C., Structure and biogenesis of the cell walls of grasses, Ann. Rev. Plant Physiol. Plant Mol. Biol. 47 (1996) 445-476.

[6] Carpita N.C., Gibeaut D.M., Structural models of primary-cell walls in flowering plants -consistency of molecular-structure with the physical-properties of the walls during growth, Plant J. 3 (1993) 1-30.

[7] Chen L.M., Carpita N.C., Reiter W.D., Wilson R.H., Jeffries C., McCann M.C., A rapid method to screen for cell-wall mutants using discriminant analysis of Fourier transform infrared spectra, Plant J. 16 (1998) 385-392.

[8] Cosgrove D.J., Assembly and enlargement of the primary cell wall in plants, Annu. Rev. Cell Dev. Biol. 13 (1997) 171-201.

[9] Dorrington K.L., McCrum N.G., Elastin as a rubber, Biopolymers 16 (1977) 1201-1222.

[10] Fenwick K.M., Jarvis M.C., Apperley D.C., Estimation of polymer rigidity in cell walls of growing and nongrowing celery collenchyma by solid-state nuclear magnetic resonance in vivo, Plant Physiol. 115 (1997) 587-592. 
[11] Foster T.J., Ablett S., McCann M.C., Gidley M.J., Mobility-resolved ${ }^{13} \mathrm{C}$ NMR spectroscopy of primary plant cell walls, Biopolymers 39 (1996) 51-66.

[12] Goldberg R., Morvan C., Jauneau A., Jarvis M.C., Methyl-esterification, de-esterification and gelation of pectins in the primary cell wall, in: Visser J., Voragen A.G.J. (Eds.), Pectins and Pectinases, Elsevier, Amsterdam, 1996, pp. 166-189.

[13] Ha M.A., Apperley D.C., Jarvis M.C., Molecular rigidity in dry and hydrated onion cell walls, Plant Physiol. 115 (1997) 593-598.

[14] Ha M.A., Evans B.W., Apperley D.C., Jarvis M.C., Rigid and flexible polymers in onion cell walls, in: Visser J., Voragen A.G.J. (Eds.), Pectins and Pectinases, Elsevier, Amsterdam, 1996, pp. 561-568.

[15] Ha M.A., Jardine W.G., Jarvis M.C., Solid-state C-13 NMR of cell walls in wheat bran, J. Agricult. Food Chem. 45 (1997) 117-119.

[16] Hamad W.Y., Eichhorn S., Deformation micromechanics of regenerated cellulose fibers using raman spectroscopy, J. Eng. Mat. Technol. -Trans. ASME 119 (1997) 309-313.

[17] Hardy B.J., Sarko A., Molecular dynamics simulations and diffraction-based analysis of the native cellulose fibre: structural modelling of the I- $\alpha$ and I- $\beta$ phases and their interconversion, Polymer 37 (1996) 1833-1839.

[18] Harris B., Composites, in: Vincent J.F.V., Currey J.D. (Eds.), The Mechanical Properties of Biological Materials, Cambridge University Press, Cambridge, 1980, pp. 37-74.

[19] Hepworth D.G., Vincent J.F.G., The mechanical properties of xylem tissue from tobacco plants (Nicotiana tabacum 'Samsun'), Ann. Bot. 81 (1998) 751-759.

[20] Hiller S., Jeronimidis G., Fracture in potato tuber parenchyma, J. Mat. Sci. 31 (1996) 2779-2796.

[21] Horii F., Hirai A., Kitamaru R., CP/MAS C-13 NMRspectra of the crystalline components of native celluloses, Macromolecules 20 (1987) 2117-2120.

[22] Irwin P.L., Pfeffer P.E., Gerasimowicz W.V., Pressey R., Sams C.E., Ripening-related perturbations in apple cell-wall nuclear-spin dynamics, Phytochemistry 23 (1984) 2239-2242.

[23] Jarvis M.C., Control of thickness of collenchyma cell walls by pectins, Planta 187 (1992) 218-220.

[24] Jarvis M.C., Intercellular separation forces generated by intracellular pressure, Plant Cell Environ. 21 (1998) 1307-1310.

[25] Jarvis M.C., Apperley, D.C., Chain conformation in concentrated pectic gels: evidence from ${ }^{13} \mathrm{C}$ NMR, Carboh. Res. 275 (1995) 131-145.

[26] Jarvis M.C., Fenwick K.M., Apperley D.C., Crosspolarisation kinetics and proton $\mathrm{nmr}$ relaxation in polymers of Citrus cell walls, Carboh. Res. 288 (1996) $1-14$.

[27] Jarvis M.C., Forsyth W., Duncan H.J., A survey of the pectic content of nonlignified monocot cell walls, Plant Physiol. 88 (1988) 309-314.
[28] Koh T.H., Melton L.D., Newman R.H., Solid-state C-13 nmr characterization of cell walls of ripening strawberries, Can. J. Bot. -Rev. Can. Bot. 75 (1997) 1957-1964.

[29] Knox J.P., Linstead P.J., King J., Cooper C., Roberts $\mathrm{K}$., Pectin esterification is spatially regulated both within cell walls and between developing tissues of root apices, Planta 181 (1990) 512-521.

[30] Liang C.Y., Marchessault R.H., Infrared spectra of crystalline polysaccharides. I. Hydrogen bonds in native celluloses, J. Polym. Sci. 37 (1959) 385-395.

[31] Lin T.T., Pitt R.E., Rheology of apple and potato tissue as affected by cell turgor, J. Texture Stud. 17 (1986) 291-313.

[32] McCann M.C., Chen L., Roberts K., Kemsley E.K., Sene C., Carpita N.C., Stacey N.J., Wilson R.H., Infrared microspectroscopy: sampling heterogeneity in plant cell wall composition and architecture, Physiol. Plant. 100 (1997) 729-738.

[33] McCann M.C., Hammouri M., Wilson R., Belton P., Roberts K., Fourier-transform infrared microspectroscopy is a new way to look at plant-cell walls, Plant Physiol. 100 (1992) 1940-1947.

[34] McCann M.C., Wells B., Roberts K., Direct visualization of cross-links in the primary plant-cell wall, J. Cell Sci. 96 (1990) 323-334.

[35] MacKay A.L., Wallace J.C., Sasaki K., Taylor I.E.P., Investigation of the physical structure of the primary plant cell wall by proton magnetic resonance, Biochemistry 27 (1988) 1467-1473.

[36] Marchessault R.H., Application of infrared spectroscopy to cellulose and wood polysaccharides, Pure Appl. Chem. 5 (1962) 107-129.

[37] Marchessault R.H., Liang C.Y., Infrared spectra of crystalline polysaccharides. VIII. Xylans, J. Polym. Sci. 59 (1962) 357-378.

[38] Michell A.J., Studies of cellulose transformations using 2nd derivative FTIR spectroscopy, Cellul. Chem. Technol. 27 (1993) 3-15.

[39] Morikawa H., Hayashi R., Senda M., Infrared analysis of pea stem cell walls and oriented structure of matrix polysaccharides in them, Plant Cell Physiol. 19 (1978) 1151-1159.

[40] Newman R.H., Nuclear magnetic resonance study of spatial relationships between chemical components in wood cell walls, Holzforschung 46 (1992) 205-210.

[41] Newman R.H., Ha M.A., Melton L.D., Molecular ordering of cellulose in apple cell walls, J. Agricult. Food Chem. 42 (1994) 1402-1406.

[42] Niklas K.J., Plant Biomechanics: an Engineering Approach to Plant Form and Function, University of Chicago Press, Chicago, 1992.

[43] Nilsson S.B., Hertz C.H., Falk S., On the relation between turgor pressure and tissue rigidity. II. Theoretical calculations on model systems, Physiol. Plant. 11 (1958) 818-837.

[44] Noda I., Two-dimensional infrared spectroscopy, J. Am. Chem. Soc. 111 (1989) 8116-8118. 
[45] Raven J.A., The evolution of vascular land plants in relation to supracellular transport processes, Adv. Bot. Res. 5 (1977) 153-219.

[46] Renard C.M.G.C., Jarvis M.C., A cross-polarization, magic-angle-spinning, C-13-nuclear-magnetic-resonance study of polysaccharides in sugar beet cell walls, Plant Physiol. 119 (1999) 1315-1322.

[47] Rihouey C., Morvan C., Jauneau A., Demarty M., In-vivo content of inorganic cations in cells and cell-walls of flax seedlings during their development, Plant Physiol. Biochem. 33 (1995) 509-517.

[48] Roy S., Vian B., Roland J.C., Immunocytochemical study of the deesterification patterns during cell wall autolysis in the ripening of cherry tomato, Plant Physiol. Biochem. 30 (1992) 139-146.

[49] Sene C.F.B., McCann M.C., Wilson R.H., Grinter R., Fourier-transform Raman and Fourier-transform infrared-spectroscopy - an investigation of 5 higherplant cell-walls and their components, Plant Physiol. 106 (1994) 1623-1631.

[50] Smith B.G., Harris P.J., Melton L.D., Newman R.H., The range of mobility of the non-cellulosic polysaccharides is similar in primary cell walls with different polysaccharide compositions, Physiol. Plant. 103 (1998) 233-246.
[51] Stejskal, E.O., Memory, J.D., High Resolution NMR in the Solid State. Fundamentals of CP/MAS, Oxford University Press, New York, 1994.

[52] Stewart D., Wilson H.M., Hendra P.J., Morrison I.M., Fourier-transform infrared and Raman spectroscopic study of biochemical and chemical treatments of oak wood (Quercus rubra) and Barley (Hordeum vulgare) straw, J. Agricult. Food Chem. 43 (1995) 2219-2225.

[53] Tang H., Belton P.S., Proton relaxation in plant cell walls and model systems, in: Belton P.S., Hills B.P., Webb G.A. (Eds.), Advances in Magnetic Resonance in Food Science, Royal Society of Chemistry, Cambridge, 1998, pp. 166-184.

[54] Terashima N., Atalla R.H., Vanderhart D.L., Solid state $\mathrm{nmr}$ spectroscopy of specifically C-13-enriched lignin in wheat straw from coniferin, Phytochemistry 46 (1997) 863-870.

[55] Tsuboi M., Infrared spectrum and crystal structure of cellulose, J. Polym. Sci. 25 (1957) 159-171.

[56] Young R.J., Raman spectroscopy and mechanical properties, in: Spells S.J. (Ed.), Characterization of Solid Polymers. New Techniques and Developments, Chapman and Hall, London, 1992, pp. 224-275. 